\title{
From History Book to Digital Humanities Database: The Basic Annals of the Shiji - ERRATUM
}

Bin Li, Yaxin Li, Qian Yang, Yaqi Wang and Rui Chen

Doi: https://doi.org/10.1017/jch.2020.24, Published online by Cambridge University Press: 12 August 2020

The author names of this article (1) should appear as follows:

Bin Li, Yaxin Li, Qian Yang, Yaqi Wang and Rui Chen

\section{References}

(1) Li, B., Li, Y., Yang, Q., Wang, Y., \& Chen, R. (2020). From History Book to Digital Humanities Database: The Basic Annals of the Shiji. Journal of Chinese History, 4(2), 528-536. Cambridge University Press. J. Kim, V. Patil, J. Chun, H. Park, S. Seo, and Y. Kim (n.d.) MRS Advances, 1-8, doi: $10.1557 /$ adv.2020.24 (2020).

Cite this article: Li B, Li Y, Yang Q, Wang Y, Chen R (2021). From History Book to Digital Humanities Database: The Basic Annals of the Shiji - ERRATUM. Journal of Chinese History 5, 169. https://doi.org/ $10.1017 /$ jch.2020.44 